\title{
Aspectos medioambientales a considerar en la formación de los socios cooperativistas ${ }^{1}$
}

(Environmental aspects to consider in the training of cooperatives members)

\author{
Francisco Javier Arrieta Idiakez ${ }^{2}$ \\ Universidad de Deusto (España)
}

Sumario: 1. Introducción. 2. El impacto que la exposición a determinados medios o ambientes puede ocasionar sobre los socios y su trabajo. 3. El impacto del trabajo de la cooperativa en el medio ambiente. 4. La búsqueda de nuevos mercados en la economía verde o azul. 5. Conclusiones. 6. Bibliografía.

Summary: 1. Introduction. 2. The impact that the exposure to certain atmospheres and environments may cause on cooperatives members and their work. 3. The impact of the cooperatives' work on the environment. 4. The search for new markets in the green or blue economy. 5. Conclusions. 6. Bibliography.

Resumen: El objetivo de este artículo consiste en responder a la pregunta de por qué las cooperativas deben centrar su atención en la formación de sus socios y trabajadores en aspectos medioambientales. Como principal hipótesis, se considera que, básicamente, son tres los motivos que conducen a la preocupación por el medio ambiente en las cooperativas y, por ende, a la necesidad de formación en dicha materia, en coherencia con el $5 .^{\circ}$ principio cooperativo.

1 Este trabajo forma parte del Proyecto de Investigación titulado «Las cooperativas como instrumento de política de empleo ante los nuevos retos del mundo del trabajo» (RTI2018-097715-B-I00). El proyecto ha sido financiado por el Ministerio de Ciencia, Innovación y Universidad del Gobierno español, la Agencia Estatal de Investigación y el Fondo Europeo de Desarrollo Regional de la Unión Europea, en el marco de la Convocatoria correspondiente a 2018 de Proyectos de I+D+i «Retos de investigación» del Programa Estatal de I+D+i orientado a los retos de la sociedad.

Asimismo, este trabajo fue expuesto como ponencia en el Congreso «El principio de educación, formación e información de las cooperativas. Consecuencias jurídicas y económicas derivadas de su aplicación práctica», organizado por la Asociación Internacional de Derecho Cooperativo, la Academia Vasca de Derecho y la Facultad de Derecho de la Universidad de Deusto, y celebrado en la Universidad de Deusto, los días 13 y 14 de noviembre de 2019.

2 Profesor titular de Derecho del Trabajo y de la Seguridad Social de la Universidad de Deusto. Email: javier.arrieta@deusto.es. 
En ese sentido, en primer lugar, se abordará el impacto que la exposición a determinados medios o ambientes puede ocasionar sobre los socios y trabajadores de las cooperativas. Ello conlleva la necesidad de estudiar las formas en las que se organiza y gestiona la prevención frente a los riesgos ambientales en las cooperativas, así como el preguntarse por las particularidades que estas presentan al respecto.

En segundo lugar, se analizará el impacto del trabajo de la cooperativa en el medio ambiente. Por consiguiente, también se tratará la forma en la que dicho impacto puede gestionarse en las cooperativas ante el mandato que trae causa del 7. ${ }^{\circ}$ principio cooperativo.

Finalmente, se profundizará en la importancia que tiene considerar el medio ambiente a efectos de poder buscar nuevos mercados en la economía verde o azul.

Desde el punto de vista metodológico, se seguirán, por una parte, los métodos descriptivo y comparativo para analizar la normativa aplicable en la materia, y, por otra parte, el método propositivo, para responder a aquellas cuestiones no contempladas en la normativa.

Palabras clave: Cooperativas; medio ambiente; formación; prevención; economías verdes y azules.

Abstract: The purpose of this paper lies in answering the question of why cooperatives need to focus the attention on the training of their members and workers in environmental aspects. As the main hypothesis, we consider that there are three reasons that lead to the concern of cooperatives about the environment and, therefore, to the need of training in this issue, in coherence with the fifth cooperative principle.

In this sense, firstly, we will address the impact that the exposure to certain means or environments can cause on the cooperative members and workers. It entails the need to study the ways in which the prevention is organized and managed in front of environmental risks in cooperatives, as well as to see the peculiarities of cooperatives in this regard.

Secondly, we will study the impact of the cooperative work in the environment. Therefore, we will address the way in which that impact can be managed in cooperatives before the mandate derived from the seventh cooperative principle.

Finally, we will delve into the importance of considering environment for the purpose of looking for new markets in the green and blue economy.

From a methodological perspective, we will follow, on the one hand, the descriptive and comparative methods in order to analyse the applicable rules applicable in the subject, and, on the other hand, the proactive method in order to give an answer to the issues that are not contemplated in regulations.

Keywords: Cooperatives; environment; training; prevention; green and blue economies. 


\section{Introducción}

Los principios cooperativos, que establece la Alianza Cooperativa Internacional, organización de carácter consultivo de la ONU e institución que une y representa a todas las cooperativas del mundo, constituyen las directrices mediante las cuales las cooperativas ponen en práctica sus valores. Es más, como recuerda la Ley 11/2019, de 20 de diciembre, de Cooperativas de Euskadi ${ }^{3}$, los principios y valores del cooperativismo deben ser destacados en el marco o dentro del concepto más amplio de la Economía Social, que no es un concepto solo teórico, sino toda una realidad constatada en su cuantificación, excelencia empresarial e indiscutible y esperanzadora utilidad social (cfr. Exposición de Motivos, apartado I). No en vano, conforme a lo establecido por la Ley 5/2011, de 29 de marzo, de Economía Social ${ }^{4}$, para alcanzar el estatus de entidad de Economía Social es necesario que las entidades enumeradas como tales en el artículo 5, entre las que se encuentran las cooperativas, se rijan por los principios orientativos del artículo 4, además de realizar actividades económicas y empresariales y cumplir la exigencia finalista de la satisfacción bien del interés colectivos de sus integrantes, bien el interés general económico y social, o de ambos $^{5}$.

De ahí que, como hace la Ley 11/2019, de 20 de diciembre, de Cooperativas de Euskadi, resulte acertado introducir en los textos normativos, junto a la definición o concepto de cooperativa, el deber que esta tiene de ajustar su estructura y funcionamiento a los principios cooperativos (cfr. artículo 1.2). Con otras palabras, el respeto a tales principios en la práctica diaria de la cooperativa es una obligación.

Entre los principios cooperativos, a los efectos de este estudio, se encuentra, enumerado como quinto principio, el relativo a la educación, formación e información. Concretamente, respecto a la formación, el Informe sobre la Declaración de la Alianza Cooperativa Interna-

3 BOPV de 30 de diciembre de 2019, núm. 247

4 BOE de 30 de marzo de 2011, núm. 76.

5 Paniagua Zurera, M. (2011, p. 66). En el mismo sentido, es preciso que más allá de la genérica afirmación realizada en la Exposición de Motivos de la Ley 5/2011, de que todas las entidades mencionadas «comparten los principios orientadores de la Economía Social (cfr. apartado II), debe superarse el nomem iuris genérico de cada entidad para centrarse en la realidad subyacente de cada caso concreto y observar que se cumplen los principios de Economía Social tanto en las reglas internas como en el funcionamiento diario de las entidades en cuestión» [Arrieta Idiakez, F.J. (2014, p. 40)]. 
cional sobre la Identidad Cooperativa (1995), señala que este «significa asegurar que todos los que están implicados en las cooperativas tengan las habilidades necesarias para llevar a cabo sus responsabilidades eficazmente» ${ }^{6}$.

Dicha definición, conlleva la necesidad de que los socios comprendan, asuman, interioricen y pongan en práctica el resto de principios cooperativos.

Precisamente, este estudio centra la atención en la conexión que presenta el principio de formación con los aspectos medioambientales a considerar por las cooperativas, teniendo en cuenta que el séptimo principio cooperativo, bajo la rúbrica «Interés por la Comunidad», establece que las cooperativas «tienen una responsabilidad de trabajar a un ritmo constante para la protección medioambiental» de las comunidades a las que están estrechamente ligadas? ${ }^{7}$.

Ahora bien, partiendo de dicha responsabilidad, la verdad es que la preocupación en las cooperativas por el medio ambiente obedece a tres razones:

(a) Abordar el impacto que la exposición a determinados medios o ambientes puede ocasionar sobre los socios y su trabajo.

(b) Abordar el impacto del trabajo de la cooperativa en el medio ambiente.

(c) Buscar nuevos mercados en la economía verde o azul.

Teniendo claro que los socios no pueden obviar dicha responsabilidad medioambiental, no es menos cierto que dicho principio aboga por que sean los socios quienes decidan «en qué profundidad y de qué forma específica una cooperativa debe hacer sus aportaciones a su comunidad» 8 .

Pero considerando las tres razones aludidas parece evidente que las aportaciones deben ser importantes. De ahí la necesidad de formar a los socios en la materia. Estamos ante otra forma de generar bienestar. Ante una forma no artificial, dado que no es posible sostener que solo la generación de bienes mercantiles genera dicho bienestar, en la medida en que existe una premisa previa, a saber, la propia existencia del planeta y del ser humano?

No en vano, la preocupación por el medio ambiente se vincula necesariamente al concepto de trabajo decente que maneja la OIT,

6 MacPherson, I. (1995, p. 30).

7 MacPherson, I. (1995, p. 32).

8 Ibidem.

9 En este sentido, véase Escribano Gutiérrez, J. (2015, pp. 135-136). 
entendido, de un modo extensivo, como aquel trabajo productivo desarrollado en condiciones de libertad, equidad, seguridad y dignidad $^{10}$. Ello debe servir para combatir la idea de que limitando los gastos en los acuerdos relativos al medioambiente laboral se ayuda a reducir $\operatorname{costes}^{11}$. Ciertamente, ello puede repercutir negativamente en la salud tanto de los socios o trabajadores, como de la ciudadanía, en general. Además, de todo ello pueden derivarse consecuencias negativas para la empresa, bien porque genere rechazo entre sus clientes, bien porque pueda llegar a ser sancionada por la Administración.

En esa línea, previamente, y como consecuencia del condicionante que supone para las cooperativas el séptimo principio respecto a su actitud para con el medio ambiente, debe precisarse una cuestión, como punto de partida fundamental a la hora de abordar cada una de las tres razones mencionadas: la relación existente entre la naturaleza y el trabajo, en tanto que ambas no pueden ser consideradas como puras y meras mercancías, sino que como valores en sí mismos y vinculadas entre sí.

En ese sentido, cabe recordar que la Declaración de Filadelfia de 10 de mayo de 1944, relativa a los fines y objetivos de la OIT, reafirma como uno de los principios fundamentales sobre los cuales está basada la OIT, que «el trabajo no es una mercancía».

Es más, como ha manifestado la doctrina científica, «no es fácil separar los límites del riesgo profesional y del riesgo ecológico puro, ya que las fronteras entre uno y otro a veces son movedizas, dada la convergencia del Derecho Medioambiental y del Derecho del Trabajo en la necesidad de protección de las personas» ${ }^{12}$.

En verdad, como ha señalado la doctrina científica, «existe una interacción recíproca entre ambos, ya que la tutela adecuada del medio ambiente natural o exterior solo podrá conseguirse desde una perspectiva integrada que contemple la acción de las organizaciones productivas tanto en sus efectos externos como en sus efectos internos. Es más, la protección medioambiental en su dimensión externa acabará incidiendo, significativamente, también en una mejora del medio ambiente de trabajo y viceversa, la mejora en la protección del medio ambiente de trabajo acabará, significativamente, incidiendo en una mejora del medio ambiente natural o externo a la empresa» ${ }^{13}$.

\footnotetext{
10 Monereo Pérez, J.L. y Perán Quesada, S. (2018, p. 3).

11 Servais, J.M. (2012, p. 5).

12 Escribano Gutiérrez, J. (2015, pp. 138-139).

13 Gutiérrez Pérez, M. (2010, p. 5).
} 
Desde el punto de vista práctico, así lo demuestra la Ley francesa núm. 2009-967, de 3 de agosto de 2009, que supone la clara confluencia entre las normas de Derecho medioambiental y el Derecho del Trabajo, al obligar a la empresa a informar y dar participación a los representantes de los trabajadores en todo aquello que implicara un riesgo al medio ambiente externo. Se generaliza con ello la normativa hasta entonces residenciada en la Ley Bachelot de 30 de julio de 2003, específica para empresas cuya actividad es potencialmente peligrosa para el medio ambiente, que traía causa de la explosión de un stock de nitrato de amonio en la empresa química AZF en Tolouse, el 21 de septiembre de 2001, que produjo 31 muertos, 2500 heridos graves, unos 8.000 heridos leves y la evacuación de un área metropolitana de cientos de miles de personas.

Por ello, «es evidente que una tutela efectiva del medio ambiente interior conllevará una reducción del impacto sobre el ambiente externo de la empresa y, en sentido contrario, una protección del medio ambiente externo generará la consiguiente mejora de las condiciones de vida y trabajo de trabajadores» ${ }^{14}$. Tal y como señala el Papa Francisco en su Carta Encíclica Laudato Si, sobre el cuidado de la casa común, de 24 de mayo de 2015, «no hay dos crisis separadas, una ambiental y otra social, sino una sola y compleja crisis socio-ambiental» (apartado 139) ${ }^{15}$.

Una vez realizada esta introducción, a continuación, se centrará la atención en cada una de las razones mencionadas que conducen a que las cooperativas se preocupen por el medio ambiente y realicen aportaciones al respecto. Realmente, su concreción permitirá también determinar el alcance de las necesidades formativas.

\section{El impacto que la exposición a determinados medios o ambientes puede ocasionar sobre los socios y su trabajo}

Para el análisis del impacto que la exposición a determinados medios o ambientes puede ocasionar sobre los socios y su trabajo, debe partirse del Convenio OIT núm. 148 de 1977, sobre medio ambiente de trabajo, dado que establece por vez primera la relación existente entre, por una parte, la protección de la seguridad y salud de los trabajadores y, por otra parte, el medio ambiente, con el objetivo de prevenir

14 Escribano Gutiérrez, J. (2015, p. 142).

15 Esta Encíclica puede consultarse en: http://www.vatican.va/content/francesco/es/ encyclicals/documents/papa-francesco_20150524_enciclica-laudato-si.html. 
y limitar los riesgos profesionales debidos a la contaminación del aire, el ruido y las vibraciones, y, en consecuencia, proteger a los trabajadores contra tales riesgos ${ }^{16}$.

Posteriormente, el Convenio OIT núm. 155, de 1981, sobre seguridad y salud de los trabajadores, trasciende el mero marco del espacio físico de la empresa para abarcar también el medio ambiente del trabajo como fuente de riesgos laborales a proteger. En efecto, la novedad que supone este convenio radica en que, si bien aún se basa, principalmente, en la protección de la seguridad y salud de los trabajadores, "avanza en la configuración del «medio ambiente de trabajo» como bien a defender, aproximándose así, a la salvaguardia del medio ambiente ${ }^{17}$. Asimismo, se ha destacado de este convenio la especial atención que dedica a la formación, las calificaciones y la motivación de las personas para el logro de niveles adecuados de seguridad y salud en el trabajo a todos los niveles ${ }^{18}$.

En la UE el artículo 153 del TFUE se refiere al «entorno del trabajo, para proteger la salud y la seguridad de los trabajadores».

En su desarrollo, la Directiva 89/391/CEE, de 12 de junio de 1989, relativa a la aplicación de medidas para promover la mejora de la seguridad y de la salud de los trabajadores en el trabajo ${ }^{19}$, en sus considerandos, de entrada, se refiere a que «los trabajadores pueden estar expuestos en su lugar de trabajo y a lo largo de toda su vida profesional a la influencia de factores ambientales peligrosos».

Ya el apartado 2.g) del artículo 6, considera como principio general de prevención «planificar la prevención buscando un conjunto coherente que integre en ella la técnica, la organización del trabajo, las condiciones de trabajo, las relaciones sociales y la influencia de los factores ambientales en el trabajo».

Y el apartado 3.c) del artículo 6 establece que «el empresario deberá, habida cuenta el tipo de actividades de la empresa y / o del establecimiento: procurar que la planificación y la introducción de nuevas tecnologías sean objeto de consultas con los trabajadores y / o sus representantes, por lo que se refiere a las consecuencias para la seguridad y la salud de los trabajadores, relacionadas con la elección de los equipos, el acondicionamiento de las condiciones de trabajo y el impacto de los factores ambientales en el trabajo».

\footnotetext{
16 Rodríguez-Piñero y Bravo-Ferrer, M. (1999, p. 8).

17 Pérez Amorós, F. (2017, p. 218).

18 Rodríguez-Piñero y Bravo Ferrer, M. (2009, p. 4).

19 DOCE de 29 de junio de 1989, L 183.
} 
En España, la Ley 31/1995, de 8 de noviembre, de Prevención de Riesgos Laborales (LPRL) ${ }^{20}$, define, en su artículo 4.7.b) las «condiciones de trabajo» como "cualquier característica del mismo que pueda tener una influencia significativa en la generación de riesgos para la seguridad y la salud del trabajador. Quedan específicamente incluidas en esta definición: La naturaleza de los agentes físicos, químicos y biológicos presentes en el ambiente de trabajo y sus correspondientes intensidades, concentraciones o niveles de presencia».

En el artículo 5.3, bajo la rúbrica, "Objetivos de la política», se señala que las Administraciones Públicas «podrán adoptar programas específicos dirigidos a promover la mejora del ambiente de trabajo y el perfeccionamiento de los niveles de protección. Los programas podrán instrumentarse a través de la concesión de los incentivos que reglamentariamente se determinen que se destinarán especialmente a las pequeñas y medianas empresas».

Por su parte, el artículo 15.1.g) recoge entre los principios de la acción preventiva: «Planificar la prevención, buscando un conjunto coherente que integre en ella la técnica, la organización del trabajo, las condiciones de trabajo, las relaciones sociales y la influencia de los factores ambientales en el trabajo».

En materia de consulta y participación de los trabajadores, el artículo 33.1.a) establece la obligación del empresario de «consultar a los trabajadores, con la debida antelación, la adopción de las decisiones relativas a: La planificación y la organización del trabajo en la empresa y la introducción de nuevas tecnologías, en todo lo relacionado con las consecuencias que estas pudieran tener para la seguridad y la salud de los trabajadores, derivadas de la elección de los equipos, la determinación y la adecuación de las condiciones de trabajo y el impacto de los factores ambientales en el trabajo».

En materia de Delegados de Prevención, el artículo 36.2.a) dispone que «en el ejercicio de las competencias atribuidas a los Delegados de Prevención, estos estarán facultados para: Acompañar a los técnicos en las evaluaciones de carácter preventivo del medio ambiente de trabajo, así como, en los términos previstos en el artículo 40 de esta Ley, a los Inspectores de Trabajo y Seguridad Social en las visitas y verificaciones que realicen en los centros de trabajo para comprobar el cumplimiento de la normativa sobre prevención de riesgos laborales, pudiendo formular ante ellos las observaciones que estimen oportunas».

20 BOE de 10 de noviembre de 1995, núm. 269. 
Por otro lado, tampoco cabe descartar que el trabajador pueda ser sancionado si no cumple con el deber de vigilancia en materia de ambiente de trabajo, dado que conforme al artículo 29 tiene la obligación de velar por su propia seguridad y salud en el trabajo y respecto a aquellas otras personas a las que pueda afectar su actividad profesional.

Ahora bien, tras analizar el marco normativo de referencia, la pregunta que cabe realizar es cómo se proyecta todo ello en las cooperativas.

Pues bien, la LPRL prevé expresamente ya en el apartado 3 de su Exposición de Motivos que «el ámbito de aplicación de la Ley incluye (...) a los socios trabajadores o de trabajo de los distintos tipos de cooperativas».

Ello está en sintonía con el marco político y papel de los gobiernos que establece la Recomendación OIT núm. 193, de 20 de junio de 2002, sobre la promoción de las cooperativas, conforme al cual "las políticas nacionales deberían, especialmente: promover la adopción de medidas relativas a la seguridad y salud en el trabajo» (cfr. artículo 8.1.g).

Más concretamente, el artículo 3.1 de la LPRL establece como la LPRL y sus normas de desarrollo "serán aplicables a las sociedades cooperativas, constituidas de acuerdo con la legislación que les sea de aplicación, en las que existan socios cuya actividad consista en la prestación de un trabajo personal, con las peculiaridades derivadas de su normativa específica».

Además, este no es un planteamiento novedoso, ya que la Ley 3/1987, de 2 de abril, General de Cooperativas ${ }^{21}$, ya contemplaba la sujeción de los socios cooperativistas a las normas de seguridad e higiene.

Incluso la actual Ley 27/1999, de 16 de julio, de Cooperativas'22, establece que "serán de aplicación a los centros de trabajo y a los socios trabajadores las normas sobre salud laboral y sobre la prevención de riesgos laborales, todas las cuales se aplicarán teniendo en cuenta las especialidades propias de la relación societaria y autogestionada de los socios trabajadores que les vincula con su cooperativa» (cfr. artículo 80.5).

En la misma línea, la Ley 11/2019, de 20 de diciembre, de Cooperativas de Euskadi, respecto a las cooperativas de trabajo asociado,

21 BOE de 8 de abril de 1987, núm. 84.

22 BOE de 17 de julio de 1999, núm. 170. 
prevé que «serán de aplicación a los centros de trabajo de estas cooperativas y a sus personas socias las normas generales sobre prevención de riesgos laborales» (cfr. artículo 103.7). En cualquier caso, este precepto se aplica también a los socios de trabajo que prestan sus servicios en otras modalidades de cooperativas.

De todos modos, no cabe olvidar que conforme a la Disposición Adicional tercera de la LPRL "esta Ley, así como las normas reglamentarias que dicte el Gobierno (...) constituyen legislación laboral, dictada al amparo del artículo 149.1.7. a de la Constitución». Con otras palabras, tratándose de una materia de competencia exclusiva del Estado, no hay margen de interpretación y aplicación por parte las legislaciones autonómicas sobre cooperativas. Pero nada obsta para que las cooperativas instrumenten una mejora de los derechos y una mayor exigencia de las obligaciones preventivas normativas por la vía de la autorregulación interna (estatutos sociales y reglamentos de régimen interno). Ello, obviamente, afecta a la formación en materia de medio ambiente de trabajo.

Dicho todo esto, cabe preguntarse qué peculiaridades son las existentes para con las cooperativas en materia preventiva.

Así, del análisis de la LPRL se deduce que tales peculiaridades se producen, con la consiguiente modulación o ajuste, entre otras, en la siguiente cuestión: las formas de representación en materia preventiva de los socios cooperativistas y, en su caso, de los trabajadores asalariados.

Se trata de una cuestión que afecta, precisamente, al medio ambiente del trabajo, en tanto en cuanto dicha representación es la que ostenta funciones específicas al respecto. Y relacionado también con ello, las peculiaridades se extienden, igualmente, al cómputo de los «trabajadores» integrantes de la plantilla a los efectos preventivos.

De este modo, respecto a los delegados de prevención ${ }^{23}$, que son los representantes de los socios y trabajadores con funciones específicas en materia de prevención de riesgos laborales, la Disposición Adicional décima de la LPRL diferencia dos situaciones:

23 Conforme al artículo 35.2 de la LPRL, debe estarse a la siguiente escala:

—De 50 a 100 trabajadores: 2 Delegados de Prevención.

-De 101 a 500 trabajadores: 3 Delegados de Prevención.

-De 501 a 1.000 trabajadores: 4 Delegados de Prevención.

—De 1.001 a 2.000 trabajadores: 5 Delegados de Prevención.

—De 2.001 a 3.000 trabajadores: 6 Delegados de Prevención.

—De 3.001 a 4.000 trabajadores: 7 Delegados de Prevención.

—De 4.001 en adelante: 8 Delegados de Prevención. 
(a) En las sociedades cooperativas que no cuenten con asalariados deberá estar previsto en sus Estatutos o ser objeto de acuerdo en Asamblea General (autorregulación interna).

(b) Cuando, además de los socios que prestan su trabajo personal, existan asalariados se computarán ambos colectivos. Y en este caso, la designación de los Delegados de Prevención se realizará conjuntamente por los socios que prestan trabajo y los trabajadores asalariados 0 , en su caso, los representantes de éstos ${ }^{24}$.

Asimismo, los delegados de prevención constituirán, junto a igual número de personas designadas por la cooperativa, el Comité de Seguridad y Salud en las cooperativas de 50 o más socios y trabajadores $^{25}$. Se trata del órgano destinado a la consulta regular y periódica de las actuaciones de la empresa en materia de prevención de riesgos laborales.

Por último, respecto a los servicios de prevención, que son los que organizan la prevención en función de la planificación realizada tras la evaluación de los riesgos, existen distintas modalidades:

(a) La designación por la cooperativa de socios o trabajadores para encargarse de la prevención. Entre otros requisitos, los designados deberán tener la capacidad necesaria, y, por tanto, forma-

24 La duda que debe resolverse en este caso es la relativa a cómo computan los trabajadores de cada uno de los colectivos, dado que la LPRL guarda silencio.

Como advierte Pérez Canet, los trabajadores pertenecientes al colectivo de asalariados de la cooperativa no suponen un problema, pues el propio artículo 35 de la LPRL establece cómo se realizará el cómputo de este colectivo a estos efectos. Así, de conformidad con dicho precepto, el volumen del colectivo de asalariados, a estos efectos, viene determinado por los trabajadores fijos de plantilla y por los trabajadores de la empresa (en este caso, en la cooperativa) vinculados por un contrato de duración determinada superior a un año. En cuanto a los asalariados temporales cuyo vínculo con la cooperativa sea inferior a un año, la LPRL establece el criterio de que estos computarán en función de la suma de los días trabajados en el período de un año anterior a la designación. Así, cada doscientos días trabajados o fracción se tomará como un trabajador más de la plantilla.

Por su parte, en lo que se refiere al cómputo del colectivo de socios trabajadores, deben computarse los socios trabajadores que estén vinculados a la cooperativa por una relación indefinida, pero también los socios trabajadores que presenten una vinculación temporal, aplicándose analógicamente respecto a estos últimos lo ya indicado para los asalariados temporales [Pérez Canet, A. (2016, p. 252)].

25 Para el cómputo de estos 50 socios y trabajadores, se entiende que, como los delegados de prevención son los que constituyen la «parte social» del Comité de Seguridad y Salud, debe extrapolarse la solución legislativa prevista para determinar el volumen de plantilla a los efectos de los delegados de prevención [Pérez Canet, A. (2016, p. 253)]. 
ción en materia de medio ambiente de trabajo, entre otros aspectos preventivos.

(b) Constitución de un servicio de prevención propio: necesariamente en cooperativas de más de 500 socios y trabajadores, así como en cooperativas de más de 250 socios y trabajadores cuando estas realicen actividades peligrosas y así lo decida la Autoridad Laboral. Como mínimo debe contar con dos de las especialidades, técnicas o ciencias preventivas [Higiene Industrial (en lo que interesa para la protección del medio ambiente del trabajo), Psicosociología, Ergonomía, Seguridad en el trabajo, Medicina de Trabajo, Política social].

(c) Concierto con un servicio de prevención ajeno.

Al margen de todo ello, por consiguiente, la cooperativa, en cuanto a empresario, debe cumplir con las rutinas preventivas, es decir, la evaluación de riesgos ${ }^{26}$, la planificación de la actividad preventiva y la puesta en práctica de la planificación, por ejemplo, a través de la entrega de EPIs, la información a los socios y trabajadores, la formación de los socios y trabajadores, la consulta y participación en materia preventiva de los socios y trabajadores en los órganos preventivos, y la vigilancia de la salud de los socios y trabajadores. De ese modo, en dichas rutinas debiera incluirse la perspectiva medioambiental ${ }^{27}$.

\section{El impacto del trabajo de la cooperativa en el medio ambiente}

Con frecuencia se comprueba que detrás de muchos atentados contra el medio ambiente se encuentran las empresas, también las cooperativas. Piénsese, de entrada, por ejemplo, en algo tan simple como el mero hecho de que el $40 \%$ de los desplazamientos con vehículos a motor tienen como origen la actividad laboral ${ }^{28}$.

Pero más allá de este concreto dato, los efectos nocivos que en la actualidad genera la actividad industrial sobre el medio ambiente se relacionan con el cambio climático, entendido por este "un cambio de clima atribuido directa o indirectamente a la actividad humana

26 A los efectos de este estudio interesan los riesgos provocados por agentes físicos: ruido, vibraciones, radiaciones, iluminación, temperatura; agentes químicos; y agentes biológicos: bacterias, protozoos, virus, hongos y gusanos parásitos.

27 Morato García, R.M. (2009, pp. 23-24).

28 Falguera Baró, M.A. (2013, p. 197). 
que altera la composición de la atmósfera mundial y que se suma a la variabilidad natural del clima observada durante períodos de tiempo comparables» ${ }^{29}$, la drástica reducción de la biodiversidad en el planeta y el impacto de las sustancias tóxicas y de las no biodegradables (v.gr. la plastificación de nuestros mares).

Ciertamente, el modelo de producción de la actual sociedad industrial e incluso postindustrial necesita de importantes recursos naturales en forma de imputs del proceso productivo: aire, agua, materias primas y energía. Así, no cabe olvidar que los recursos naturales pueden ser renovables o no renovables $y$, por tanto, finitos. $Y$ los renovables pueden estar bien o mal gestionados, lo que en su caso puede suponer su agotamiento. Igualmente, las fuentes de energía pueden ser renovables y limpias o derivadas de las reservas de petróleo, carbón, gas o uranio y, por tanto, finitas y contaminantes.

Asimismo, como consecuencia de los bienes y servicios objeto de producción se generan una serie de outputs del proceso: emisiones, vertidos, ruidos, residuos sólidos, residuos peligrosos etc. que tienen un impacto negativo en el medio y revelan ineficiencias del sistema productivo.

Por todo ello, se concluye que el modelo de desarrollo actual es insostenible, no solo desde el punto de vista ambiental, sino que también desde la perspectiva económica, social y del empleo ${ }^{30}$.

Así, conforme a dicho informe, «si continúa predominando el escenario actual, los modelos de producción y consumo que producen muchos residuos junto a la degradación del suelo, la deforestación, la sobreexplotación pesquera y el cambio climático resultarán en un aumento de la escasez de agua y en el incremento del precio de los alimentos, la energía y otros productos básicos. Esta situación agravará problemas como la pobreza y las desigualdades, así como la malnutrición y la inseguridad alimentaria» ${ }^{31}$.

Por todo ello surge la normativa de ordenación del medio ambiente a nivel mundial, regional e interno, con normas como la Convención Marco de las Naciones Unidas sobre el Cambio Climático, de 9 de mayo de 1992 y el Protocolo de Kioto derivada de la misma; la Decisión 1386/2013/UE del Parlamento Europeo y del Consejo, de 20 de noviembre de 2013, relativa al Programa General de Acción de la Unión en materia de Medio Ambiente hasta 2020 «Vivir

29 Artículo 1.2 de la Convención Marco de las Naciones Unidas sobre el Cambio Climático de 1992.

30 OIT (2012, p. VII).

31 Ibidem. 
bien, respetando los límites de nuestro planeta» ${ }^{32}$; diversas leyes autonómicas como la Ley 16/2017, de 1 de agosto, del cambio climático (Cataluña) $^{33}$ o la Ley 10/2019, de 22 de febrero, de cambio climático y transición energética (Islas Baleares) ${ }^{34}$.

Derivado de todo ello, afloran los peligros de la mala gestión ambiental por parte de las empresas. Peligros que son de naturaleza social, laboral y económica. Así, junto a los clásicos riesgos para la seguridad y la salud de los trabajadores, que ya han sido analizados, se producen las sanciones que traen causa del incumplimiento de la legislación medioambiental y que se traducen en una disminución de la competitividad, la mala imagen y la pérdida de confianza ante los clientes y los consumidores.

Ante todo ello, las empresas comienzan a reaccionar y a integrar en su gestión el control de las consecuencias medioambientales derivadas de su producción o actuación hacia el exterior, es decir, hacia la comunidad en la que se ubica. Dicho con otras palabras, comienzan a adquirir conciencia de su responsabilidad en la gestión racional de los recursos, en las necesidades de protección del medio ambiente y en la mejora de la calidad de vida de las personas.

En concreto, en el caso de las cooperativas, ello resulta ser un mandato derivado del séptimo principio cooperativo, según se ha adelantado.

La gran cuestión es entonces saber cómo se puede llevar a cabo dicha gestión. Pero independientemente de ello, parece evidente que esa gestión, cualquiera que sea la forma de implementarla, conlleva la necesidad de formar a los socios y trabajadores de la cooperativa en cuestión. Con otras palabras, la gestión y formación en materia medioambiental quedan fusionadas en la sociedad cooperativa como una obligación que esta debe cumplir no solo desde la plasmación del séptimo principio cooperativo por imperativo legal, sino que desde el convencimiento y el estilo propio del ser y del hacer o actuar que la deben caracterizar e identificar.

Además, en la fórmula cooperativa, como consecuencia del segundo principio cooperativo, relativo a la gestión democrática por parte de los socios, y que consiste en que los socios deben participar activamente en la fijación de las políticas y de la toma de decisiones de las cooperativas, no basta con la mera colaboración a la que se refiere el artículo 64.7.c) del Real Decreto Legislativo 2/2015,

32 DOUE de 28 de diciembre de 2012, L 354.

33 BOE de 28 de septiembre de 2017, núm. 234.

34 BOE de 13 de abril de 2019, núm. 89. 
de 23 de octubre, por el que se aprueba el texto refundido de la Ley del Estatuto de los Trabajadores (TRLET), que prevé como competencia del comité de empresa «colaborar con la dirección de la empresa para conseguir el establecimiento de cuantas medidas procuren el mantenimiento y el incremento de la productividad, así como la sostenibilidad ambiental de la empresa, si así está pactado en los convenios colectivos». Es decir, que la última palabra la tiene el empresario.

Por consiguiente, en las cooperativas deben implementarse formas de participación efectivas en la gestión medioambiental ${ }^{35}$. Para ello caben distintas posibilidades:

(a) Ampliar las competencias de los delegados de prevención y de los comités de salud y seguridad, lo que puede suponer una sobrecarga de funciones.

(b) Crear delegados medioambientales especializados en la normativa medioambiental que afecte a la cooperativa.

Así, la función de los delegados medioambientales podría consistir en colaborar con la Dirección de la cooperativa en la mejora de la acción medioambiental de la cooperativa, así como en promover y fomentar la cooperación de los socios y trabajadores en la ejecución de la normativa medioambiental, ejercer una labor de vigilancia y control del cumplimiento de las políticas adoptadas en materia medioambiental, y proponer iniciativas, jornadas de sensibilización o proyectos relacionados con la protección del medio ambiente.

Para su designación se seguiría el procedimiento ya indicado para con los delegados de prevención, es decir, tendrían que ser nombrados por los socios y trabajadores de la cooperativa, o ser directamente designados por los representantes de los trabajadores. Obviamente, estos delegados debieran estar formados sobre la normativa medioambiental que afecta a su cooperativa ${ }^{36}$.

Creada la forma participativa para encauzar la gestión medioambiental, la Dirección de la cooperativa y los delegados medioambientales pueden implantar las políticas medioambientales de la cooperativa a través de distintos sistemas que tengan por objetivo integrar el medio ambiente en todos los niveles de la cooperativa asignando funciones y responsabilidades derivadas a los socios y trabajadores.

35 Sobre la importancia de la participación de los trabajadores véase Olmo Gascón, A. (2017, p. 66).

36 Álvarez Cuesta, H. (2016, p. 115). 
Asimismo, el Consejo Social, en su función de asesoramiento, debiera emitir informe preceptivo sobre las normas adoptadas en la cooperativa sobre materia medioambiental.

En concreto, respecto a los sistemas para implantar y, posteriormente, certificar o verificar las políticas medioambientales de la cooperativa, pueden utilizarse la Norma UNE-EN-ISO 14001:201537 y el Reglamento (CE) 1221/2009 del Parlamento Europeo y del Consejo, de 25 de noviembre de 2009, relativo a la participación voluntaria de organizaciones en un sistema comunitario de gestión y auditoría medioambientales (EMAS) ${ }^{38}$.

En ambos casos deben seguirse cuatro etapas generales e interrelacionadas, a saber, la planificación, la aplicación, la verificación, y la revisión ${ }^{39}$.

Precisamente, en la fase de aplicación, que es la base para dirigir y coordinar eficazmente los recursos asignados al sistema de gestión

37 Como ejemplo de lo que supone la Norma UNE-EN-ISO 14001:2015 en cuanto a sistema de gestión ambiental, puede citarse su reconocimiento expreso en el Código de Conducta del Modelo de Organización y Gestión del Grupo Cikautxo, que incluye a las Sociedades Controladas por Cikautxo, S. Coop., y se extiende, en la medida de lo posible, a Proveedores, Personas Asociadas y Clientes. Así, en dicho Código de Conducta se establece que el Grupo está comprometido en minimizar el impacto ambiental de su actividad, y que, por ello, dispone de un sistema de gestión ambiental certificado según la norma ISO 14001 que asegura el cumplimiento de la legislación y apuesta por la mejora continua. A continuación, se señala que «Las personas de la organización deben esforzarse por minimizar el impacto ambiental derivado de la utilización de las instalaciones, activos y recursos puestos a su disposición. Así mismo, se comprometen activa y responsablemente con la conservación del medio ambiente y deben conocer y cumplir la política, los procedimientos e instrucciones del Sistema de Gestión Ambiental vigentes en su lugar de trabajo y en el ámbito de su responsabilidad. El Grupo Cikautxo adquiere el compromiso de mejorar las condiciones de las instalaciones desde el punto de vista ambiental» (https://www.cikautxo.es/downloads/CIKAUTXO\%20-\%20Code\%20 of\%20Conduct.pdf).

Debe destacarse de este Código de Conducta el hecho de que se extienda, en la medida de lo posible, a Proveedores, Personas Asociadas y Clientes, pues con ello se genera lo que viene denominándose un «deber de influencia» del Grupo respecto de los colaboradores externos en virtud del cual es posible incluir una especie de cláusula social de respeto del medio ambiente en los acuerdos establecidos con los mismos, como condición de establecimiento de relaciones comerciales. En virtud de tales cláusulas de influencia, el Grupo se obliga a informar a los colaboradores, es decir, empresas contratistas y proveedores, sobre el alcance de las disposiciones medioambientales que viene aplicando en su seno, y a invitarles a adherirse a las mismas [López Rodríguez, J. (2018, p. 358)].

38 DOUE de 22 de diciembre de 2009, L 342.

39 Ansola González, G. (2017, pp. 92-95, 98-100). 
medioambiental, cobra importancia la formación del personal implicado 40 .

En ese sentido, debe fijarse la capacidad necesaria de las personas que realizan los trabajos de control, que afecte a su desempeño ambiental y su idoneidad para cumplir los requisitos legales y otros requisitos, debe asegurarse de que estas personas sean competentes, basándose en su educación ambiental, formación o experiencia apropiadas, o en caso contrario deben determinarse y proporcionarse las necesidades de formación asociadas con los aspectos medioambientales y el sistema de gestión medioambiental de la organización.

A tales efectos, cabe recordar la importancia del fondo de educación y promoción de las cooperativas, pues el mismo está destinado a la formación y educación de los socios cooperativistas y de los trabajadores de la cooperativa en los principios y valores cooperativos, o en materias específicas de su actividad societaria o laboral y demás actividades cooperativas; a la difusión del cooperativismo; a la promoción de las relaciones intercooperativas y otras actividades en beneficio del entorno local o de la comunidad en general; así como a acciones de protección medioambiental ${ }^{41}$.

\section{La búsqueda de nuevos mercados en la economía verde o azul}

Del informe Empleos verdes: Hacia el trabajo decente para un mundo sostenible y con bajas emisiones de carbono. Mensajes normativos y principales para los responsables de la toma de decisiones, se concluye que las posibilidades de empleo de los sectores económicos respetuosos con el medio ambiente son significativamente mayores que las de sectores de fuerte impacto medioambiental ${ }^{42}$.

Es decir, se percibe que una buena gestión ambiental además de garantizar la estabilidad y continuidad de la empresa, conlleva la mejora de la salud y la seguridad, y favorece la creación de nuevos empleos.

De ahí que se vea en el empleo verde y en el empleo azul una oportunidad para la creación del empleo. En esa línea, y a sensu con-

40 Pérez Amorós, F. (2010, p. 196).

41 Mata Diestro, H. (2018, p. 303).

42 Informe elaborado en 2008 por Worldwatch Institute para el Programa de las Naciones Unidas para el Medio Ambiente (PNUMA), con las aportaciones, entre otros, de la OIT, la Organización Internacional de Empleadores (OIE) y la Confederación Sindical Internacional (CSI). 
trario, puede constatarse como desde el prisma del Derecho del Trabajo la jurisprudencia contempla supuestos de despidos objetivos relacionados con la necesaria adaptación de la empresa a determinadas exigencias medioambientales ${ }^{43}$.

Así, para la OIT sólo son empleos verdes aquellos que conjuguen el trabajo decente con, o bien una actividad económica respetuosa con el medio ambiente o bien aquéllos que proporcionen productos o servicios verdes ${ }^{44}$.

Por su parte, el concepto de economía azul, según el Parlamento Europeo, "abarca una amplia gama de sectores económicos relacionados con los mares y los océanos, incluyendo sectores tradicionales o establecidos y sectores emergentes, como lo siguientes: pesca, acuicultura, transportes marítimos y fluviales, puertos y logística, turismo, navegación de recreo y de crucero, construcción y reparación de buques, obras marítimas y de defensa de la franja costera, prospección y explotación de recursos minerales en el mar, explotación de la energía eólica marina y de la energía de los mares y biotecnología». Y se considera que el desarrollo de esta economía azul «debe centrarse en actividades económicas sostenibles que respondan a las necesidades de las generaciones actuales y futuras y generen prosperidad para la sociedad $»^{45}$.

Y como advierte la Resolución del Parlamento Europeo, de 8 de julio de 2015, sobre «la iniciativa de empleo verde: aprovechar el potencial de la creación de empleo de la economía verde» ${ }^{46}$, o se deduce de la Resolución del Parlamento Europeo, de 8 de septiembre de 2015, sobre «Explotar el potencial de la investigación y la innovación en la economía azul para crear puestos de trabajo y crecimiento», debe hacerse hincapié en las competencias profesionales para los empleos verdes y azules.

Sin duda, el quinto principio cooperativo, relativo a la educación, formación e información, debe jugar aquí un papel relevante, tanto para la adaptación de las cooperativas a las nuevas realidades como para la creación de nuevas cooperativas.

43 Por todas, STSJ Canarias/Santa Cruz de Tenerife (4. ${ }^{a}$ ), de 28 de mayo de 2008 (Ar. 353/08).

44 Álvarez Cuesta, H. (2016, p. 24).

45 Resolución del Parlamento Europeo, de 8 de septiembre de 2015, sobre «Explotar el potencial de la investigación y la innovación en la economía azul para crear puestos de trabajo y crecimiento» (DOUE de 22 de septiembre de 2017, C 316) (Considerandos A y B).

46 DOUE de 11 de agosto de 2017, C 265. 


\section{Conclusiones}

Primera. Las cooperativas deben buscar las fórmulas adecuadas para vincular el quinto principio cooperativo, en lo que atañe a la formación de socios y trabajadores, con el séptimo principio cooperativo, en lo que se refiere a la protección del medio ambiente. Se trata de un deber que trae causa tanto de la Ley 5/2011, de 29 de marzo, de Economía Social, como de la normativa cooperativa, en tanto en cuanto las cooperativas tienen el deber de ajustar su estructura y funcionamiento a los principios cooperativos.

Segunda. La protección del medio ambiente presenta en la actualidad una doble vertiente en las empresas, en el sentido de que se proyecta hacia dentro de la empresa, vinculándose claramente a la prevención de riesgos laborales, pero también hacia fuera de la empresa, en cuanto debe velar por la protección del planeta en términos de sostenibilidad que hagan posible vivir y trabajar en el mismo. Precisamente, la segunda de las vertientes cobra, si cabe, un mayor protagonismo en las cooperativas, ya que se convierte en un imperativo, al referirse el séptimo principio cooperativo al interés por la comunidad.

Del mismo modo, la sinergia de ambas vertientes se produce a través del trabajo digno o decente al que se refiere la OIT, de forma y manera que, sin protección del medio ambiente en ambas vertientes, no cabe hablar de trabajo decente o digno. Además, el trabajo decente o digno resulta inherente a la cooperativa, pues el empleo de calidad es una manifestación del tercer principio orientador de las entidades de la Economía Social, relativo a la promoción de la solidaridad interna y con la sociedad, según la Ley 5/2011, de 29 de marzo, de Economía Social, y un fin en sí mismo del cooperativismo, tal y como se deduce de la Recomendación OIT núm. 193, de 20 de junio de 2002, sobre la promoción de las cooperativas, al referirse al empleo decente y sostenible como objetivo de las cooperativas.

Tercera. Tanto la normativa internacional como la española inciden en la obligación de proteger en las empresas a los trabajadores frente a los riesgos ambientales, a través de la prevención de riesgos laborales. En concreto, la LPRL resulta también de aplicación a las cooperativas, pero con particularidades en cuanto a la forma en la que deben participar los socios y trabajadores de las cooperativas en los órganos dedicados a la defensa y organización de la prevención. Como en cualquier empresa, la cooperativa debe cumplir con las rutinas preventivas, incluyendo en las mismas también la perspectiva medioambiental. En 
ese sentido, la formación, como rutina preventiva, es fundamental para que los socios y trabajadores de la cooperativa ejerzan su labor adecuadamente en los órganos dedicados a la defensa y organización de la prevención, cuando esta se refiera a aspectos relacionados con los factores ambientales en el trabajo.

Cuarta. Teniendo en cuenta que el modelo de desarrollo actual resulta insostenible, no solo desde el punto de vista ambiental, sino que también desde la perspectiva económica, social y del empleo, se están creando normas, de distinto ámbito, para proteger el medio ambiente y sancionar a las empresas que lo dañan. De ahí que las empresas comiencen a adquirir conciencia de su responsabilidad en la gestión racional de los recursos, en las necesidades de protección del medio ambiente y en la mejora de la calidad de vida de las personas. En concreto, en el caso de las cooperativas, ello resulta ser un mandato derivado del séptimo principio cooperativo.

Quinta. La gestión medioambiental de toda empresa y, por ende, también de la empresa cooperativa, requiere la necesidad de formar en la materia a los socios y trabajadores. Además, dicha formación adquiere un mayor valor en las cooperativas, pues en la fórmula cooperativa, como consecuencia del segundo principio cooperativo, relativo a la gestión democrática por parte de los socios, no basta con la mera colaboración con la empresa, sino que deben implementarse formas de participación efectivas en la gestión medioambiental.

Sexta. En las cooperativas, como en cualquier empresa, la participación de los socios y trabajadores en la gestión medioambiental puede encauzarse y materializarse, bien ampliando las competencias de los órganos dedicados a la prevención de riesgos laborales o bien creando delegados medioambientales especializados en la normativa medioambiental que afecte a la cooperativa.

Ahora bien, el aumento del número de normas relativas al medio ambiente y las especialidades de las mismas para con la normativa de prevención de riesgos laborales hacen que la figura de los delegados medioambientales sea más adecuada. Además, en el caso de los delegados medioambientes de las cooperativas su participación debe ser algo más que una mera colaboración con la Dirección de la cooperativa.

En efecto, entre ambos debieran implantar las políticas medioambientales de la cooperativa a través de distintos sistemas que tengan por objetivo integrar el medio ambiente en todos los niveles de 
la cooperativa asignando funciones y responsabilidades derivadas a los socios y trabajadores. Asimismo, en las cooperativas debiera jugar una función importante el Consejo social, asesorando sobre las normas adoptadas sobre la materia.

Séptima. Respecto a los sistemas para implantar y, posteriormente, certificar o verificar las políticas medioambientales de la cooperativa pueden utilizarse la Norma UNE-EN-ISO 14001:2015 y el Reglamento (CE) 1221/2009 del Parlamento Europeo y del Consejo, de 25 de noviembre de 2009 , relativo a la participación voluntaria de organizaciones en un sistema comunitario de gestión y auditoría medioambientales (EMAS).

En ambos casos deben seguirse cuatro etapas generales e interrelacionadas, a saber, la planificación, la aplicación, la verificación, y la revisión. En la fase de aplicaciones es donde cobra importancia la formación del personal implicado. A tales efectos, cabe recordar la importancia del fondo de educación y promoción de las cooperativas.

Octava. Una buena gestión ambiental, además de garantizar la estabilidad y continuidad de la empresa, conlleva la mejora de la salud y la seguridad, y favorece la creación de nuevos empleos. Por consiguiente, el empleo verde y el empleo azul constituyen verdaderos nichos de empleo. Pero para ello es esencial que los socios y trabajadores de las cooperativas adquieran las competencias profesionales adecuadas y necesarias, lo que requiere, asimismo, la puesta en práctica del quinto principio cooperativo, relativo a la educación, formación e información, tanto para que las cooperativas existentes se adapten a la nueva realidad como para que puedan crearse nuevas cooperativas acordes a esa nueva realidad.

\section{Bibliografía}

ÁLVAREZ CUESTA, H. 2016. Empleos verdes: una aproximación desde el Derecho del Trabajo. Albacete: Bomarzo.

ANSOLA GONZÁLEZ, G. 2017. "Gestión Medioambiental de Organizaciones». En Empleos verdes y prevención de riesgos laborales» (Agra Viforcos, B., Dir.). Valencia: Tirant lo Blanch.

ARRIETA IDIAKEZ, F.J. 2014. "Concreción de las entidades de la Economía Social». En REVESCO, Revista de Estudios Cooperativos, núm. 116.

ESCRIBANO GUTIÉRREZ, J. 2015. «Trabajo y medio ambiente: perspectivas jurídico-laborales». En La ecología del trabajo. El trabajo que sostiene la vida (MORA CABELLO DE ALBA, L., Dir.). Albacete: Bomarzo. 
FALGUERA BARÓ, M.A. 2013. «La negociación colectiva medioambiental en Cataluña». En Aspectos medioambientales de las relaciones laborales. Participación, salud laboral y empleo (RIVAS VALLEJO, P., Dir.). Granada: Laborum.

GUTIÉRREZ PÉREZ, M. 2010. «La protección del medio ambiente como factor condicionante de las relaciones laborales». En Revista Doctrinal Aranzadi Social, núm. 3. BIB $2010 \backslash 742$.

LÓPEZ RODRíGUEZ, J. 2018. «El papel de los Acuerdos Marco Internacionales en la Preservación del Medio Ambiente». En Health at Work, Ageing and Environmental Effects on Future Social Security and Labour Law Systems (CEREJEIRA NAMORA, N., MELLA MÉNDEZ, L. et at., Ed.). Cambridge: Cambridge Scholars Publising.

MACPHERSON, I. 1995. Co-operative principles for the $21^{\text {st }}$ century. Geneva: International Co-operative Alliance.

MATA DIESTRO, H. 2018. «Fondos sociales obligatorios: la justificación de su irrepartibilidad en los orígenes del cooperativismo y del movimiento obrero organizado». En Boletín de la Asociación Internacional de Derecho Cooperativo, núm. 53. DOI: http://dx.doi.org/10.18543/baidc-532018pp289-307

MONEREO PÉREZ, J.L. y PERÁN QUESADA, S. 2018. «Configuración y sentido político-jurídico y técnico-jurídico». En El trabajo decente (MONEREO PÉREZ, J.L., GORELLI HERNÁNDEZ, J. y DEL VAL TENA, A.L., Dirs.). Granada: Comares.

MORATO GARCÍA, R.M. 2009. «Destinados a converger: Integración de las dimensiones medioambiental y de prevención de riesgos laborales» En Seguridad y Medio Ambiente, núm. 114.

OIT. 2012. HACIA EL DESARROLLO SOSTENIBLE: OPORTUNIDADES DE TRABAJO DECENTE E INCLUSIÓN SOCIAL EN UNA ECONOMIAA VERDE. GINEBRA: OFICINA INTERNACIONAL DEL TRABAJO.

OLMO GASCÓN, A. 2017. «Tratamiento del empleo verde en la normativa internacional y europea (especialmente en el Pilar Europeo de Derechos Sociales): la precisa reconfiguración de sus elementos jurídico-laborales». En El futuro del trabajo que queremos (MORA CABELLO DE ALBA, L. y RODRÍGUEZ FERNÁNDEZ, M.L., Coords.). Albacete: Bomarzo.

PANIAGUA ZURERA, M. 2011. Las empresas de la Economía Social. Más allá del comentario a la Ley 5/2011, de Economía Social. Madrid: Marcial Pons.

PÉREZ AMORÓS, F. 2017. "Derecho del Trabajo, derecho al empleo, y medio ambiente». En Los actuales cambios sociales y laborales: nuevos retos para el mundo del trabajo. Volumen 4. Cambios en la relación laboral individual y nuevos retos para el contrato de trabajo (España, Portugal, México, Francia) (MELLA MÉNDEZ, L., Dir.). Berna: Peter Lang.

PÉREZ AMORÓS, F. 2010. «Derecho del trabajo y medio ambiente: unas notas introductorias». En Revista Técnico Laboral, vol. 32, núm. 124.

PÉREZ CANET, A. 2016. "La prevención de riesgos laborales en las cooperativas». En Análisis práctico de la Ley de Prevención de Riesgos Laborales (TOSCANI GIMÉNEZ, D. y ALEGRE NUENO, M., Dirs.). Valladolid: Lex Nova - Thomson Reuters. 
RODRÍGUEZ-PIÑERO Y BRAVO-FERRER, M. 2009. «Promover la seguridad y salud en el medio ambiente de trabajo». En Relaciones Laborales, núm. 12, LA LEY 12551/2009.

RODRÍGUEZ-PIÑERO Y BRAVO-FERRER, M. 1999. «Medio ambiente y relaciones de trabajo». En Temas Laborales, núm. 50.

SERVAIS, J.M. 2012. "El trabajo decente: la visión de la OIT y su puesta en práctica (1)». En Relaciones Laborales, núm. 15, LA LEY 16447/2012. 


\section{Derechos de autor}

El Boletín de la Asociación Internacional de Derecho Cooperativo es una revista de acceso abierto lo que significa que es de libre acceso en su integridad inmediatamente después de la publicación de cada número. Se permite su lectura, la búsqueda, descarga, distribución y reutilización legal en cualquier tipo de soporte sólo para fines no comerciales y según lo previsto por la ley; sin la previa autorización de la Editorial (Universidad de Deusto) o el autor, siempre que la obra original sea debidamente citada (número, año, páginas y DOI si procede) y cualquier cambio en el original esté claramente indicado.

\section{Copyright}

The International Association of Cooperative Law Journal is an Open Access journal which means that it is free for full and immediate access, reading, search, download, distribution, and lawful reuse in any medium only for non-commercial purposes, without prior permission from the Publisher or the author; provided the original work is properly cited and any changes to the original are clearly indicated. 